\title{
A Novel Multi-Patient Mechanical Ventilator Drive System Using Continuously Variable Transmission and Reverse Gearbox
}

\author{
Endi Sailul Haq ${ }^{\text {a }}$, Devit Suwardiyanto ${ }^{\text {a }}$, Sepyan Purnama Kristanto ${ }^{\text {a }}$, Endang Setyati ${ }^{\text {b,* }}$ \\ ${ }^{a}$ Infomatics Engineering, State Polytechnic of Banyuwangi, Banyuwangi, East Java, Indonesia \\ ${ }^{b}$ Information Technology, Institute of Science and Integrated Technology of Surabaya (ISTTS), Surabaya, East Java, Indonesia \\ Corresponding author: *endang@stts.edu
}

\begin{abstract}
In the present study, a new model of multi-mechanical ventilator drive using a continuously variable transmission (CVT) cone was presented as the main driving force to control the pressure of the BVM Ambu bag, which can produce different airflow pressures for several patients, and using a worm gear to isolate the CVT cone so as not to get the load generated from the pressure of the Ambu bag. In addition, the reverse gear transmission system is used to control the direction of rotation, and the leadscrew is used to change the rotation according to the linear translational motion of the Ambu bag pushing arm. In this system, a DC motor is used as the main driver, and a flexible tuner cable that can be connected to other ventilators is utilized. This research shows that this CVT system can reduce rotation down to $60.35 \%$ and increase rotation up to $148.26 \%$ with constant rotation input. There are 23 points of change in the position of the belt, which causes variations in the pouch pressing. The system can produce the highest and lowest pressure value at 20.2 and $0.4 \mathrm{~cm} \mathrm{H} \mathrm{H}_{2} \mathrm{O}$. Simultaneously, the rotation of the flexible tuner cable showed no significant change. However, the weakness in the CVT system is the belt friction with the cone surface causing heat and slippage. In this case, the selection of the appropriate material and belt shape can cause belt displacement easiness that important in appropriate speed for applied pressure.
\end{abstract}

Keywords-Multi-mechanical ventilator; CVT cone; worm gear; reverse gearbox; Ambu bag; COVID-19.

\section{INTRODUCTION}

Coronavirus disease 2019 (COVID-19) is a contagious disease that originated from Wuhan, Hubei Province, China, at the end of December 2019. This virus attacks the lungs and causes shortness of breath (pneumonia) [1]. The COVID-19 outbreak has spread to many countries, including Indonesia, and the World Health Organization has declared COVID-19 a global pandemic [2]. Based on statistics released by the Task Force for the Acceleration of Handling COVID-19, the number of confirmed cases in a national scale as of September 1,2020 , alone has reached $177,571(23.7 \%$ of the patients were under treatment, $72.1 \%$ recovered, and $4.2 \%$ died), which tends to increase every day [3].

Since COVID-19 attacks the respiratory system, patients infected with the disease have high risk of developing shortness of breath and respiratory failure. Respiratory failure or acute respiratory distress syndrome is a condition in which the air sacs of the lungs are filled with mucous fluid due to an infection reaction, causing the lungs to not supply oxygen during the oxygen diffusion process [4]. Consequently, the oxygen content in the body tissue (the value of tissue's saturated oxygenation $\mathrm{StO}_{2}$ ) will decrease. If not treated properly, the decreasing of StO2 levels may lead to death [5]. Therefore, external intervention is incredibly important, and a clinical instrument called a mechanical ventilator (VM) is required to perform such task.

A VM is a breathing apparatus that generates controlled pressure or airflow in the patient's airway. VMs are often used as a replacement for the chest pump function for patients who are experiencing fatigue or respiratory failure [6]-[8]. VM is inserted to maintain optimal alveolar ventilation so as to meet metabolic requirements, correct hypoxemia, and maximize oxygen transport [4], [7], [9]. Incorrect application of the VM physiology, for instance, by generating positive pressure instead of negative pressure to expand the lungs, can cause serious problems. Therefore, when applying VM, the accuracy of the indication, the patient, and the method of application should be analyzed, and possible complications must always be taken into account. In addition, the physiology of respiration must be properly understood during VM application [10]. 
Given the lack of ventilators in hospitals in Indonesia and the potential for an increase in the number of patients with COVID-19, it is necessary to have sufficient ventilators. One of the efforts to provide enough VMs to accommodate a large number of infected patients is to create a ventilator that can support several patients [9], [11]-[13]. A multi-patient ventilator means that a VM can be used to help the patient breathe simultaneously. The most difficult part of this multipatient ventilator is how to provide positive pressure to patients with different needs [12]. The purpose of this study was to create a VM prototype design using continuously variable transmission (CVT) as the main driving force to regulate the emphasis on the BVM Ambu bag, which can produce different airflow pressures for several patients.

\section{MATERIALS AND MEthods}

The concept of this VM is to connect a motor that functions as the main drive to several ventilators on one axis by utilizing the CVT mechanism. CVT mechanism functions as a separator between ventilators so that the ventilator can have different rotations and easily changes the rotation of each ventilator without changing the belt and stopping the motor rotation. Fig. 1 shows the concept developed to establish a multi-patient VM.
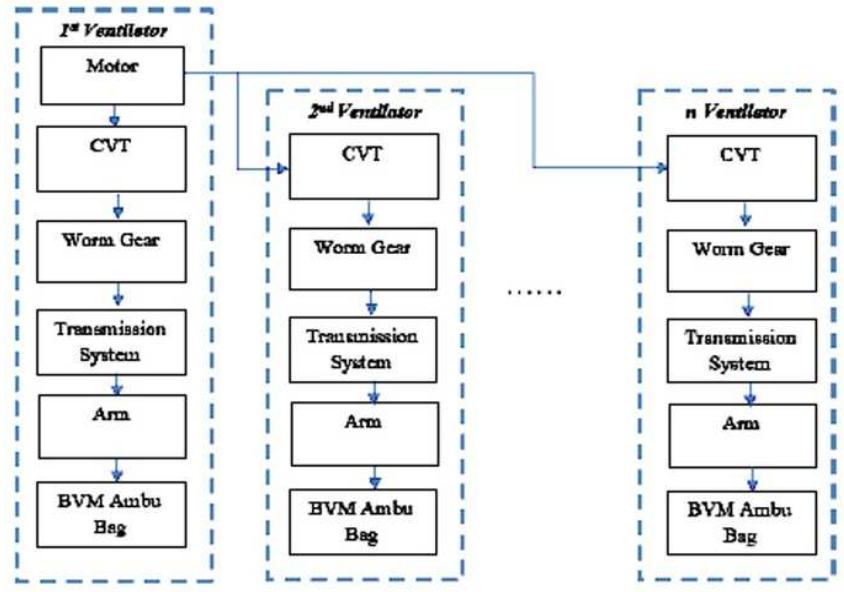

Fig. 1 Diagram of the basic principles of the ventilator for many patients

This ventilator prototype comprises a frame made of aluminum and a holder for all components using PLA material printed on a 3-D printer, which is equipped to be controlled by a microcontroller. This multi-patient VM consists of a main ventilator using a DC motor drive, as shown in Fig. 1, and a connector is connected to another ventilator.

In this study, each ventilator made has the same dimensions and specifications. Meanwhile, the difference is that there is a motor on the main ventilator. As shown in Fig. 2, driving motors are placed on the main ventilator and are connected by a flexible tuner cable with the other ventilator. The motor used in this study is a PG45 DC motor with a rotational speed of $500 \mathrm{rpm}$, maximum torque of $25 \mathrm{~kg} \mathrm{~cm}$, input voltage $24 \mathrm{~V}$, and maximum current consumption of $4 \mathrm{~A}$ and is equipped with an encoder.

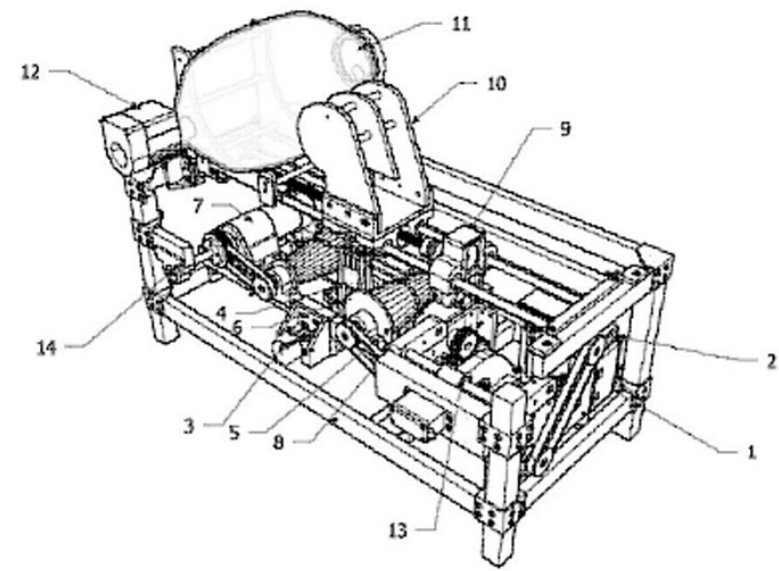

Fig. 2 Main ventilator design and all parts. 1. Microcontroller. 2. Battery. 3. CVT belt drive stepper motor. 4. CVT belt holder. 5. CVT cone. 6. Cone connecting belt. 7. Main drive DC motor. 8. Worm gear. 9. Ambulance suppression stepper motor. 10. Arm to compress BVM Ambu bag. 11. BVM Ambu bag. 12. Output hose connector and pressure sensor. 13. Reverse gearbox. 14. Flexible tuner cable (output to another ventilator)

This driving motor is connected to a CVT cone on each ventilator to increase the rotation of the CVT cone using a timing belt with a gear diameter ratio of 37 and $22 \mathrm{~mm}$. The gear ratio $\mathrm{I}=0.594$ in each CVT cone will increase by approximately 1.68 times the motor rotation. Thus, the rotation and torque of the cone can be calculated:

$$
\begin{gathered}
i=\frac{n_{2}}{n_{1}}=\frac{D_{1}}{D_{2}} \\
\tau_{2}=\tau_{1} \times \mathrm{i}
\end{gathered}
$$

where

$\mathrm{I}=$ gear ratio

$\mathrm{n}=$ number of revolutions per minute $(\mathrm{RPM})$

$\mathrm{D}=\operatorname{diameter}(\mathrm{mm})$

$\tau=$ torque (N.m)

\section{A. CVT Cone}

CVT is a transmission system widely developed in motorized vehicles [17]-[19]. CVT cone comprises two identical cones placed side by side, with each cone reversed. The cone made on this ventilator has a length of $150 \mathrm{~mm}$, largest diameter of $80 \mathrm{~mm}$, and smallest diameter of $32 \mathrm{~mm}$, as shown in Fig. 3.

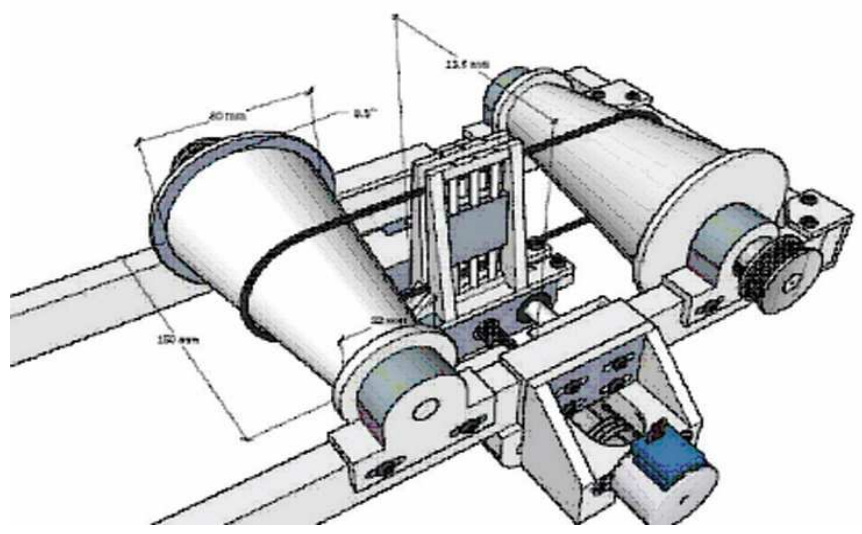

Fig. 3 CVT cone 
The average angle of the cone from the largest and the smallest is $8.5^{\circ}$. Using CVT cone on this ventilator can change the arm speed of the BVM Ambu bag suppressor according to the needs of the patients [14], [15]. Using the CVT transmission system, the rotational speed needed for the Ambu bag suppression process will be very easily provided, discussed later. In this study, the cones were made from Teflon, and the two cones were connected using a round rubber belt. The selection of this round rubber belt reduces the friction between the cone and the belt when moving the belt position from a small to a large diameter position or vice versa. To reduce the potential for slippage, the cone surface is textured with a roughness of less than $1 \mathrm{~mm}$. Fig. 4 shows the surface roughness of the cone and the realization of the CVT cone that has been made.

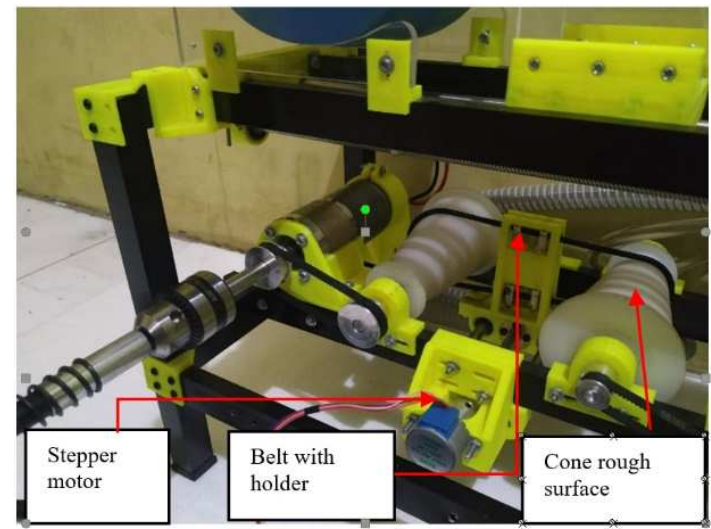

Fig. 4 Realization of CVT cone

The belt in the CVT system is placed in a belt holder. The $5 \mathrm{v}$ rotation of the $28 \mathrm{BYJ}-48$ stepper motor connected to a leadscrew which has a length of $150 \mathrm{~mm}$ as shown in Fig. 3 will drive the linear translation on the belt.

\section{B. Worm Gear}

In this study, we used a modified worm gear on a power window gearbox made of nylon-66 material with a fairly good level of transmission efficiency [16]. This ventilator uses a gear ratio of 65: 1 . The selection of worm gear is to be applied because worms can move the gear very easily, but the gear itself cannot move the worm. This is due to the shallow angle of the worm, so the gear attempts to move the worm, the friction force holds the worm in place and functions as selflocking [16].

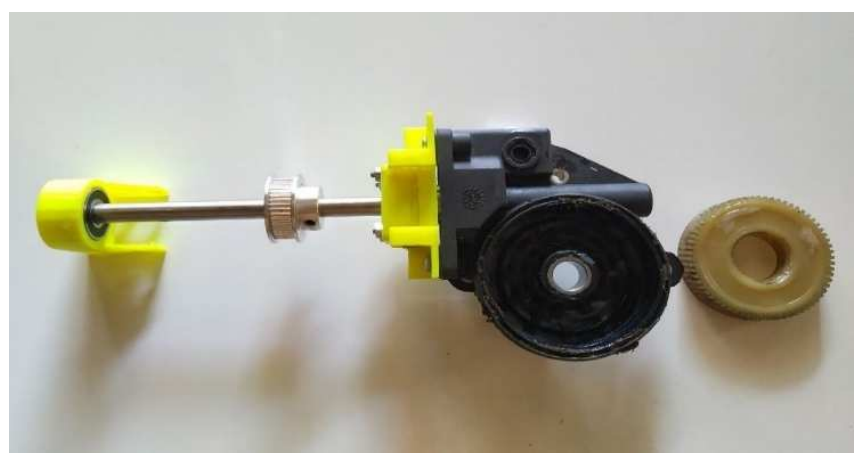

Fig. 5 Worm gear

Properties such as this are very useful for isolating CVT from being exhausted. Because in the initial prototype of making the ventilator, the CVT was connected directly to the reverse gearbox transmission system, and there was a slip between the CVT cone and the belt when the arm pressed the BVM Ambu bag. The slip is greatest when the CVT belt (no. 4 in Fig. 2) is in the position of the smallest diameter size of the second cone. So that the faster the second cone turns, the greater the slip value. The RPM measurement data are taken by considering the lowest RPM value when a slip occurs, as shown in Fig. 6.

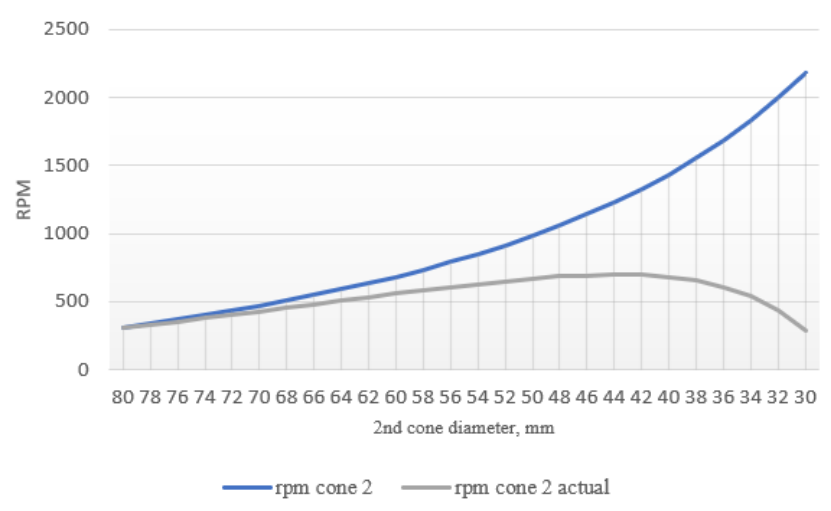

Fig. 6 Slip value on CVT without worm gear

In the present study, the efficiency and torque values of worm gear were not calculated. However, after using worm gear focusing on the RPM value on the CVT cone, the slip between the belt and the CVT cone decreased significantly.

\section{Reverse Gearbox}

A reverse gearbox is a transmission system that changes rotation [17], [18]. In this study, a reverse gear system is designed to change the direction of the worm gear's rotation output so that the reverse gearbox's rotation output can be in forward, neutral, and reverse (F-N-R) positions. The principle of reverse gear used is very simple and does not change the rotation ratio forward or backward.

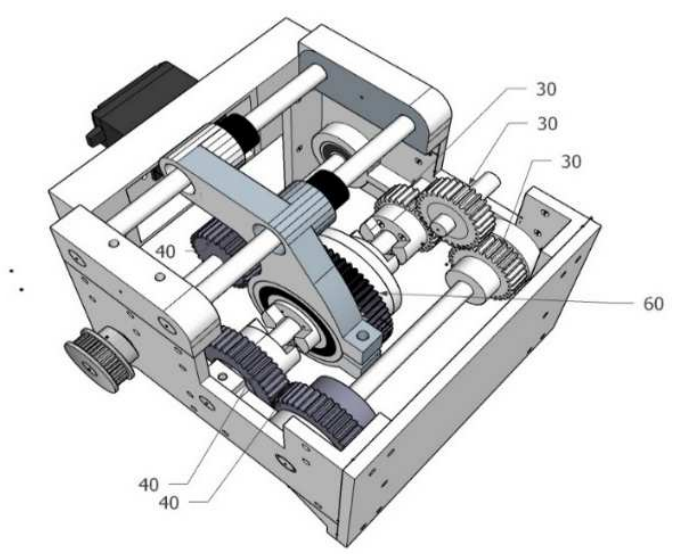

Fig. 7 Reverse gearbox design along with the diameter of each gear

Fig. 7 shows the design of the reverse gear that comprises several parts such as the input shaft, output shaft, and idle shaft (intermediary); bearing selector; hub sleeve; and gear. The input shaft has two gears with 40 and 30 teeth. Conversely, the idle shaft comprises three gears: a gear connected to a hub on one side with several teeth 40 and 30 and a middle gear connected to a hub on both sides with several teeth 60 .

$$
n_{\text {out }}=(60 / 30) n_{\text {in }}
$$




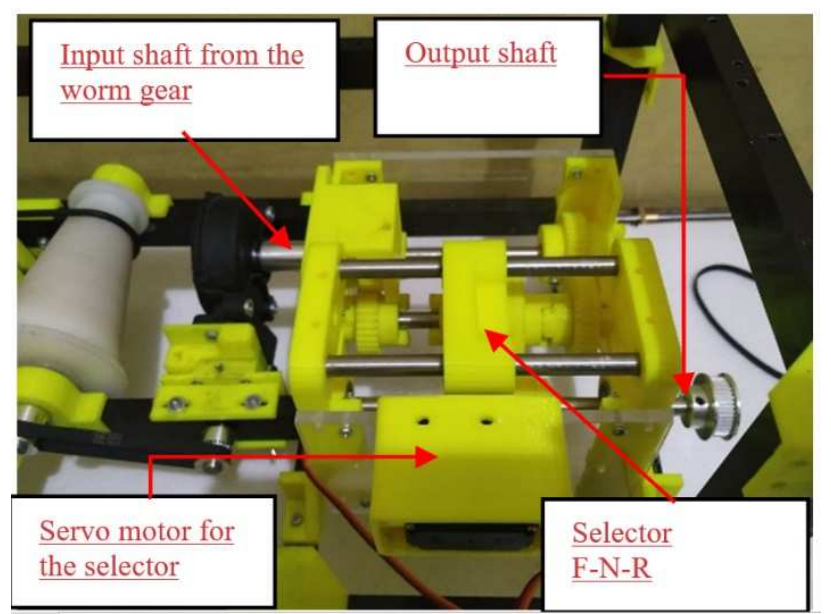

Fig. 8 Realization of the transmission system that uses a reverse gearbox

Hence, the rotation of the output shaft of this transmission system is two times greater than the rotation of the input shaft. On the idle shaft, there is also a bearing selector and hub sleeve that determine the direction of rotation of the output shaft (FN-R). The bearing selector is driven by a servo motor (Fig. 8); hence, the hubs can be connected. There is an idle gear with 24 teeth between the idle shaft and the input shaft. This idle gear changes the direction of rotation to match the input rotation. Note that the number of teeth in each gear affects the number of outputs. This helps control the ventilator system when pressing the Ambu bag because the output from the reverse gearbox has the same rotation speed when turning forward and turning backward. The calculation of both gear ratio forward (GFR) and reverse (GRR), as well as gear ratio 1 (GR1) and 2 (GR2) are shown in Equation 4-7.

$$
\begin{gathered}
G R F=\frac{T_{2}}{T_{1}}=\frac{40}{40}=1 \\
G R_{1}=T_{2} / T_{1}=24 / 30=0.8 \\
G R_{2}=T_{3} / T_{2}=30 / 24=1.25 \\
G R R=G R_{1} \times G R_{2}=0.8 \times 1.25=1 \\
\text { III.RESULTS AND DISCUSSION }
\end{gathered}
$$

\section{RESULTS AND DISCUSSION}

The experiment, conducted for the first time, aimed to count the turns on the CVT cone. The diameter of each cone influences CVT cone rotation. The change in diameter in each cone is controlled by a stepper motor, as shown in Fig. 4. The experimental results show that one stepper motor rotation will move the belt holder by $7 \mathrm{~mm}$. Thus, there are 23 belt positions on the CVT cone. Table 1 shows the comparison of the rotation of the CVT cone according to these 23 positions.

The velocity of each section is measured using a tachometer [19] but only on the output side. Note that the main drive in this system uses a DC motor connected directly to the first cone using a timing belt and pulley that has the same size as shown in Fig. 4. Hence, the motor speed equals to the speed of the first cone (Eq. 8).

$$
n_{\text {motor }}=n_{1 \text { stCone }}
$$

\begin{tabular}{|c|c|c|c|c|c|c|}
\hline $\begin{array}{c}\text { Belt } \\
\text { Position }\end{array}$ & $\begin{array}{c}\text { First cone } \\
\text { diameter }(\mathrm{mm})\end{array}$ & $\begin{array}{c}\text { Second cone } \\
\text { diameter }(\mathrm{mm})\end{array}$ & $\begin{array}{l}\text { First cone speed } \\
\text { (RPM) }\end{array}$ & $\begin{array}{c}\text { Second cone } \\
\text { speed (RPM) }\end{array}$ & $\begin{array}{c}\text { Worm gear } \\
\text { speed (RPM) }\end{array}$ & $\begin{array}{l}\text { Reverse gear } \\
\text { speed (RPM) }\end{array}$ \\
\hline 1 & 32 & 80.698 & 1243 & 493 & 8 & 15 \\
\hline 2 & 34.54 & 78.5 & 1247 & 549 & 8 & 17 \\
\hline 3 & 36.738 & 76.302 & 1242 & 598 & 9 & 18 \\
\hline 4 & 38.936 & 74.104 & 1245 & 654 & 10 & 20 \\
\hline 5 & 41.134 & 71.906 & 1247 & 713 & 11 & 22 \\
\hline 6 & 43.332 & 69.708 & 1241 & 771 & 12 & 24 \\
\hline 7 & 45.53 & 67.51 & 1241 & 837 & 13 & 26 \\
\hline 8 & 47.728 & 65.312 & 1246 & 911 & 14 & 28 \\
\hline 9 & 49.926 & 63.114 & 1242 & 982 & 15 & 30 \\
\hline 10 & 52.124 & 60.916 & 1246 & 1066 & 16 & 33 \\
\hline 11 & 54.322 & 58.718 & 1252 & 1158 & 18 & 36 \\
\hline 12 & 56.52 & 56.52 & 1246 & 1246 & 19 & 38 \\
\hline 13 & 58.718 & 54.322 & 1247 & 1348 & 21 & 41 \\
\hline 14 & 60.916 & 52.124 & 1252 & 1463 & 23 & 45 \\
\hline 15 & 63.114 & 49.926 & 1245 & 1574 & 24 & 48 \\
\hline 16 & 65.312 & 47.728 & 1240 & 1697 & 26 & 52 \\
\hline 17 & 67.51 & 45.53 & 1249 & 1852 & 28 & 57 \\
\hline 18 & 69.708 & 43.332 & 1244 & 2001 & 31 & 62 \\
\hline 19 & 71.906 & 41.134 & 1248 & 2182 & 34 & 67 \\
\hline 20 & 74.104 & 38.936 & 1249 & 2377 & 37 & 73 \\
\hline 21 & 76.302 & 36.738 & 1248 & 2592 & 40 & 80 \\
\hline 22 & 78.5 & 34.54 & 1250 & 2841 & 44 & 87 \\
\hline 23 & 80.698 & 32 & 1242 & 3083 & 47 & 95 \\
\hline
\end{tabular}

TABLE I

SPEED REDUCTION By DiAMETER ON CONE, RESPECTIVELY

As shown in Table 1, the motor rotation is constant, whereas the rotation of the second cone can vary with the displacement of the belt that connects the two cones. This CVT system can reduce rotation down to $60.35 \%$ and increase rotation up to $148.26 \%$ with the same input rotation. However, the friction $(\mu)$ that occurs between the belt and the cone creates heat, which causes a slip (v) between the belt and the cone. The friction value and slip value in the CVT system are influenced by the grip strength $(F)$ of the belt on the cone, the pitch radius of the cone $(R)$, and the rotation speed calculated by the equation [20]. 


$$
\begin{gathered}
\mu=\tau \cdot \cos \theta /(2 . F . R) \\
\Delta v=R_{1 \text { stCone }} n-v \\
\Delta v=v-R_{2 n d C o n e} \cdot n
\end{gathered}
$$

The output of the second cone rotation is connected to worm gear using a timing belt with the same pulley ratio. Thus, the rotation input on the worm gear is the rotation output on cone 2. Conversely, in the worm gearbox itself, there is a mechanism to reduce rotation with a ratio of $1: 65$. The advantage of the worm gear in this system is to isolate the CVT cone from being overloaded and to increase the torque when pressing the Ambu bag. However, the consequence is that the rotation will decrease by $98.5 \%$.

The worm gear rotation output is connected to the reverse gearbox transmission system. The reverse gearbox functions to change the direction of rotation in three positions, namely, turning right $(\mathrm{CW})$ or forward, turning left or back $(\mathrm{CCW})$, and neutral (resting). As shown in Table 1, the number of turns on the reverse gearbox becomes 2 times the worm gear rotation based on Equation 3. The experimental results show that there is no change in the speed when rotating $\mathrm{CW}$ or $\mathrm{CCW}$. However, there were a few problems when moving from neutral to $\mathrm{CW}$ or neutral to CCW. This is because the end of the pin joint on the shaft selector is square, so it has the potential for a collision to occur when changing positions. The mechanism for pressing the Ambu bag is used by an arm that moves back and forth according to the rotation of the leadscrew, as shown in Fig. 9. The resulting rotation is converted into a linear motion for forward (pressing the Ambu bag) and back (not pressing). The lead screw that is used has the following specifications: pitch width $(2 \mathrm{~mm})$, leadscrew length $(150 \mathrm{~mm})$, and diameter $(8$ $\mathrm{mm})$.

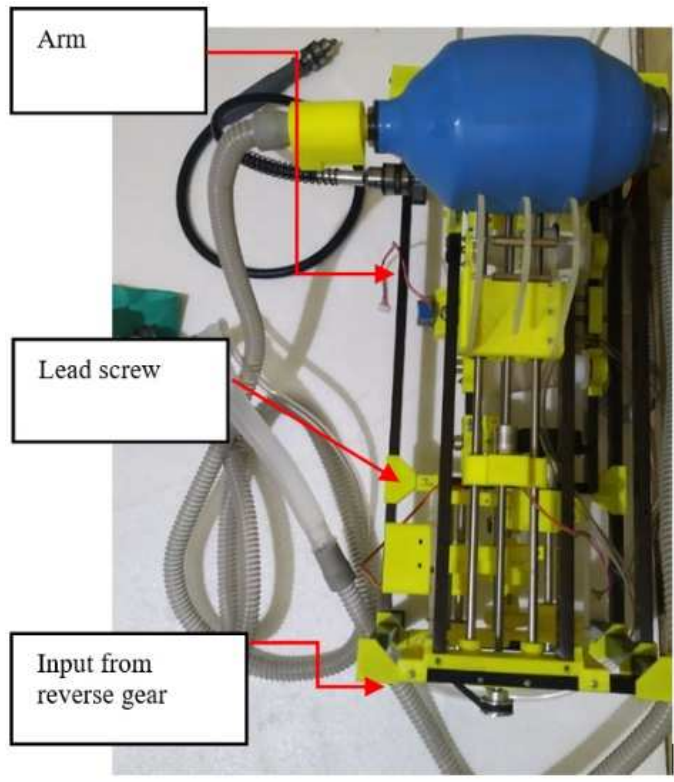

Fig. 9 Ambu bag propulsion system

The leadscrew rotation is obtained from the reverse gearbox rotation output with the ratio of the number of teeth $1: 8$. Thus, the leadscrew rotation has seven times the speed, as shown in Fig. 10. The increase in leadscrew rotation aims to get the displacement of the Ambu bag propulsion arm, which can meet the time of the inspiration process.

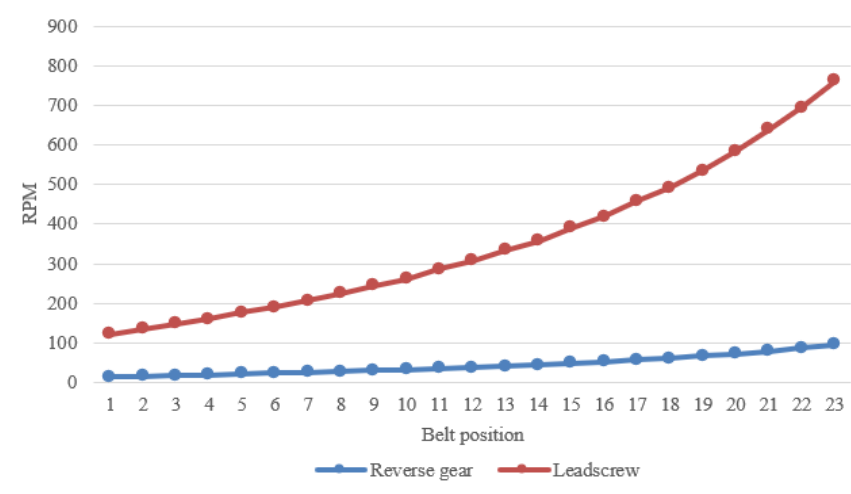

Fig. 10 The ratio of lead screw turns and reverse gearbox

The experiments conducted to test the system when pressing the Ambu bag were counting the number of turns per second on the lead screw and measuring the displacement of the Ambu bag arm. The propelling arm and the BVM Ambu bag holder are designed in such a way as to support the Ambu bag from falling and to put maximum pressure on it. The pressing arm consists of three acrylic boards arranged parallel to a semicircle at the top, as shown in Fig. 11, with a height of 116 $\mathrm{mm}$ and a support height of $124 \mathrm{~mm}$.

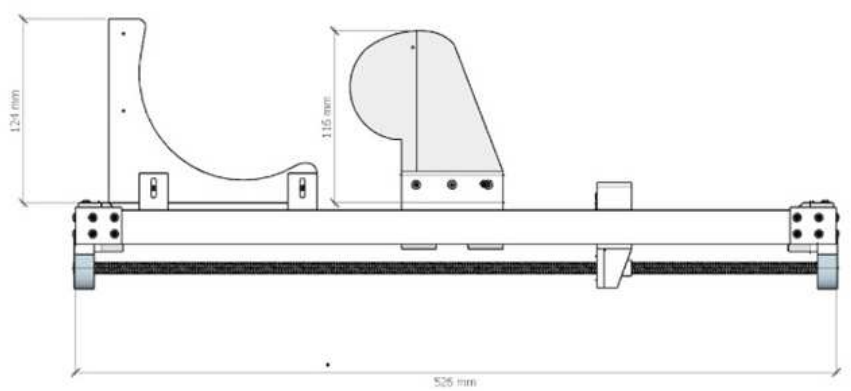

Fig. 11 design of the ambu bag BVM propelling arm

In this study, BVM Ambu bag adults with a capacity of $1500-2000 \mathrm{ml}$ of air were used [21]. The support arm is made in a stationary position, while the propelling arm will move forward according to the number of turns of the leadscrew. The propulsion arm movement will move forward if the leadscrew rotates clockwise $(\mathrm{CW})$ and will move backward if the leadscrew rotates counterclockwise $(\mathrm{CCW})$. The reverse gear transmission system determines this change of rotation direction. Fig. 12 shows the amount of airflow released by the Ambu bag based on the displacement of the propulsion arm.

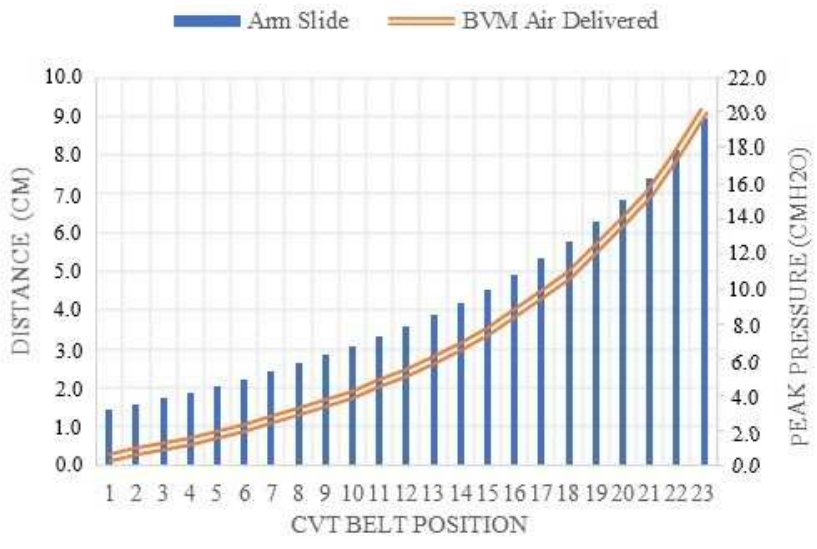

Fig. 12 Air delivered vs arm slide 
This measurement method uses a manometer, which is used to determine the peak pressure of the BVM Ambu bag. The position of the belt on the CVT is changed from the first position to the last position, whereas the position of the BVM Ambu bag pressing arm will be returned to the non-pressing position at each stage. From these data, it can be seen that the system can suppress the Ambu bag so that it produces the highest-pressure value of $20.2 \mathrm{~cm} \mathrm{H}_{2} \mathrm{O}$ and the smallest value of $0.4 \mathrm{~cm} \mathrm{H}_{2} \mathrm{O}$. At the same time, the rotation of the flexible tuner cable was also measured (No. 14, Fig. 2). The measurement results show no change in the rotation of the flexible tuner cable, as shown in Fig. 13.

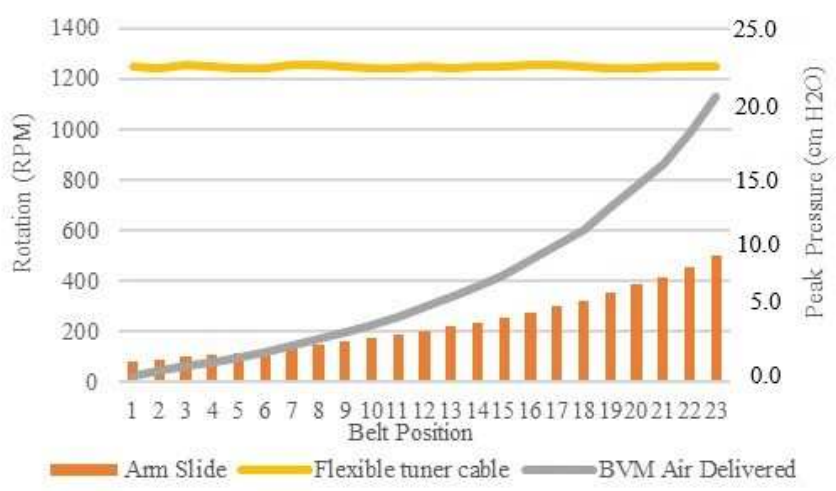

Fig. 13 Flexible Tuner Cable Rotation vs Peak Pressure

\section{IV.CONCLUSIONS}

This study applies an arm drive model that can suppress the Ambu bag to realize multi-patient VM by implementing a drive mechanism using a CVT cone, worm gear, and reverse gearbox. This can be proven by the ability of this system that there is no change in the rotation of the flexible tuner cable that can later be connected to other ventilators. The air pressure output that can be generated also varies and can be adjusted to the desired amount of pressure. However, this system has a limitation in the CVT system, in which the belt friction with the cone surface will cause heat and cause slippage. In this case, selecting the appropriate material and belt shape must be considered because the ease of displacement of the belt is very important in producing the appropriate speed for pressing the Ambu bag.

\section{ACKNOWLEDGMENT}

State Polytechnic of Banyuwangi officially supports this study.

\section{REFERENCES}

[1] Q. Ding, P. Lu, Y. Fan, Y. Xia, and M. Liu, "The clinical characteristics of pneumonia patients coinfected with 2019 novel coronavirus and influenza virus in Wuhan, China," J. Med. Virol., vol. 92, no. 9, pp. 1549-1555, Sep. 2020, doi: 10.1002/jmv.25781.

[2] R. Djalante et al., "Review and analysis of current responses to COVID-19 in Indonesia: Period of January to March 2020," Prog. Disaster Sci., vol. 6, p. 100091, Apr. 2020, doi: 10.1016/j.pdisas.2020.100091.
[3] W. R. P. COVID-19, "Peta Sebaran," covid19.go.id. https://covid19.go.id/peta-sebaran (accessed Mar. 20, 2021).

[4] Y. Yi, P. N. P. Lagniton, S. Ye, E. Li, and R.-H. Xu, "COVID-19: what has been learned and to be learned about the novel coronavirus disease," Int. J. Biol. Sci., vol. 16, no. 10, pp. 1753-1766, Mar. 2020, doi: $10.7150 /$ ijbs.45134.

[5] A. Das, "Modelling and Optimisation of Mechanical Ventilation for Critically Ill Patients," p. 166.

[6] J. S. Han et al., "Personalized Ventilation to Multiple Patients Using a Single Ventilator: Description and Proof of Concept," Crit. Care Explor., vol. 2, no. 5, p. e0118, May 2020, doi: 10.1097/CCE.0000000000000118.

[7] P. L. Silva and P. R. M. Rocco, "The basics of respiratory mechanics: ventilator-derived parameters," Ann. Transl. Med., vol. 6, no. 19, p. 376, Oct. 2018, doi: 10.21037/atm.2018.06.06.

[8] O. Garmendia et al., "Low-cost, easy-to-build noninvasive pressure support ventilator for under-resourced regions: open source hardware description, performance and feasibility testing," Eur. Respir. J., vol. 55, no. 6, Jun. 2020, doi: 10.1183/13993003.00846-2020.

[9] V. O. Kheyfets, S. Lammers, J. Wagner, K. Bartels, and B. Smith, "Use of a Single Ventilator to Support Multiple Patients: Modeling Tidal Volume Response to Heterogeneous Lung Mechanics," medRxiv, p. 2020.04.07.20056671, Apr. 2020, doi: 10.1101/2020.04.07.20056671.

[10] S. Zulfiqar, H. Nadeem, Z. Tahir, M. Mazhar, and K. M. Hasan, "Portable, Low Cost, Closed-Loop Mechanical Ventilation Using Feedback from Optically Isolated Analog Sensors," in TENCON 2018 - 2018 IEEE Region 10 Conference, Oct. 2018, pp. 1913-1916, doi: 10.1109/TENCON.2018.8650277.

[11] S. M. Kim, U. H. Lee, H. J. Kwon, J.-Y. Kim, and J. Kim, "Development of an IoT Platform for Ocean Observation Buoys," IEIE Trans. Smart Process. Comput., vol. 6, no. 2, pp. 109-116, 2017, doi: 10.5573/IEIESPC.2017.6.2.109.

[12] J. Herrmann, A. Fonseca da Cruz, M. L. Hawley, R. D. Branson, and D. W. Kaczka, "Shared Ventilation in the Era of COVID-19: A Theoretical Consideration of the Dangers and Potential Solutions," Respir. Care, vol. 65, no. 7, pp. 932-945, Jul. 2020, doi: 10.4187/respcare.07919.

[13] A. Vasan et al., "MADVent: A low-cost ventilator for patients with COVID-19," Med. Devices Sens., Jun. 2020, doi: 10.1002/mds3.10106.

[14] E. Mobedi and M. İ. C. Dede, "A Continuously Variable Transmission System Designed for Human-Robot Interfaces," in Mechanism and Machine Science, Singapore, 2021, pp. 29-41, doi: 10.1007/978-98115-4477-4_3.

[15] M. V. Čavić, M. M. Penčić, and M. Ž. Zlokolica, "Adaptive continuously variable transmission used for maintaining stationary regime of driving machine," Therm. Sci., vol. 20, no. suppl. 2, pp. 525536, 2016.

[16] J. B. Mahakal and D. Kamble, "Investigation of Performance of Plastic Worm Gear in Power Window Gearbox Application," 2016. /paper/Investigation-of-Performance-of-Plastic-Worm-GearMahakal-Kamble/d7a5afa1bfd70d815d79571c8b3a870a99a8eae9 (accessed Mar. 20, 2021).

[17] A. K. Ajay, A. J. Vadakkekara, A. Krishnan, A. K. V., A. Paul, and J. P. N., "Reverse gear mechanism on a motor cycle," AIP Conf. Proc., vol. 2247, no. 1, p. 020002, Jul. 2020, doi: 10.1063/5.0004186.

[18] K. R. S. Ansari, A., B. Shukla, P. J., and Khan, W., "Design \& fabrication of reverse gear box for go-kart \& for handicapped vehicle," Int. J. Recent Trends Eng. Res., vol. 3, no. 3, pp. 401-408, March 2017.

[19] Ellis, G., Observers in Control System. US: Academic Press, 2002.

[20] H. Nishizawa, H. Yamaguchi, H. Suzuki, M. Osawa, K. Iwatuki, and Y. Oshiumi, "Friction characteristics analysis for clamping force setup in metal V-belt type CVT," SAE Tech. Pap., vol. 40, no. 3, pp. 14-20, 2005, doi: 10.4271/2005-01-1462.

[21] B. Dafilou, D. Schwester, N. Ruhl, and A. Marques-Baptista, "It's In The Bag: Tidal Volumes in Adult and Pediatric Bag Valve Masks," West. J. Emerg. Med., vol. 21, no. 3, pp. 722-726, May 2020, doi: 10.5811/westjem.2020.3.45788. 